\title{
New Nasopharyngeal Flap for Posterior Skull-base Reconstruction: The Upper-Tongue Flap
}

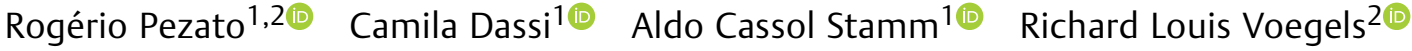 \\ 1 Departament of Otorhinolaryngology and Head and Neck Surgery, \\ Universidade Federal de São Paulo, São Paulo, SP, Brazil \\ 2 Departamento of Ophthalmology and Otorhinolaryngology, Faculdade de \\ Address for correspondence Rogerio Pezato, MD, PhD, Rua Teodoro \\ Sampaio 407, Cerqueira César, São Paulo, Brazil \\ (e-mail: pezatobau@gmail.com).
} Medicina, Universidade de São Paulo, São Paulo, SP, Brazil

Int Arch Otorhinolaryngol 2022;26(3):e467-e469.

\begin{abstract}
Introduction Reconstructions of clival resection are still challenging, and additional reconstructive methods may be necessary to achieve full coverage of the skull-base defect in patients with middle- and lower-clivus disease.

Objective To describe a new nasopharyngeal flap for the middle and lower clivus.

Methods Using nasal endoscopy in a cadaver dissection, we demonstrated a new nasopharygeal flap to cover the lower and middle clival resection.

Results We described a new nasopharyngeal flap capable of covering the lower and middle portion of the clivus.

Discussion The new nasopharyngeal flap, called the upper-tongue flap, is particularly adequate as an alternative for the reconstruction of middle and lower clivus defects,

Keywords

- nasopharynx

- flap

- nasal and it is better used in association with a nasalseptal flap in cases in which the nasalseptal flap alone does not provide enough mucosal coverage.

Conclusion The new nasopharyngeal flap can be used in the reconstruction of clival resection.
\end{abstract}

\section{Introduction}

Endoscopic endonasal resection of clival lesions is welldescribed in the literature, but is still challenging, even to the most experienced surgeons. The clivus is formed by sphenoidal and occipital portions, and it is usually divided into the upper, middle, and lower clivus. The upper clivus is located above the crossing of the trigeminal and abducens nerves. The middle clivus is located between the exits of the trigeminal and glossopharyngeal nerves, while the lower clivus is the portion between the glossopharyngeal nerve and the foramen magnum. The last two thirds are bounded anteriorly by the nasopharynx and retropharyngeal tissues. ${ }^{1,2}$

Despite the complexity of its anatomy and surgical access, the reconstruction of the clivus and posterior base of the skull following an endoscopic endonasal approach requires a special attention. Vascularized flaps, the nasoseptal flap (NSF) in particular, are the mainstay for the reconstruction of skull-base defects. ${ }^{3,4}$ However, additional reconstructive methods may be necessary to achieve full coverage of the skull-base defect in patients with middle- and lower-clivus disease. $^{5}$

\section{Objective}

The present study has the goal of presenting a new option for the reconstruction of the middle and lower-thirds of the clivus through a flap, called the upper-tongue flap (UTF), harvested starting from the roof of the nasopharynx. received

December 18, 2020

accepted

January 8, 2021

published online

November 3, 2021
DOI https://doi.org/ 10.1055/s-0041-1724094. ISSN 1809-9777.

\footnotetext{
(C) 2021. Fundação Otorrinolaringologia. All rights reserved. This is an open access article published by Thieme under the terms of the Creative Commons Attribution-NonDerivative-NonCommercial-License, permitting copying and reproduction so long as the original work is given appropriate credit. Contents may not be used for commercial purposes, or adapted, remixed, transformed or built upon. (https://creativecommons.org/ licenses/by-nc-nd/4.0/)

Thieme Revinter Publicações Ltda., Rua do Matoso 170, Rio de Janeiro, RJ, CEP 20270-135, Brazil
} 


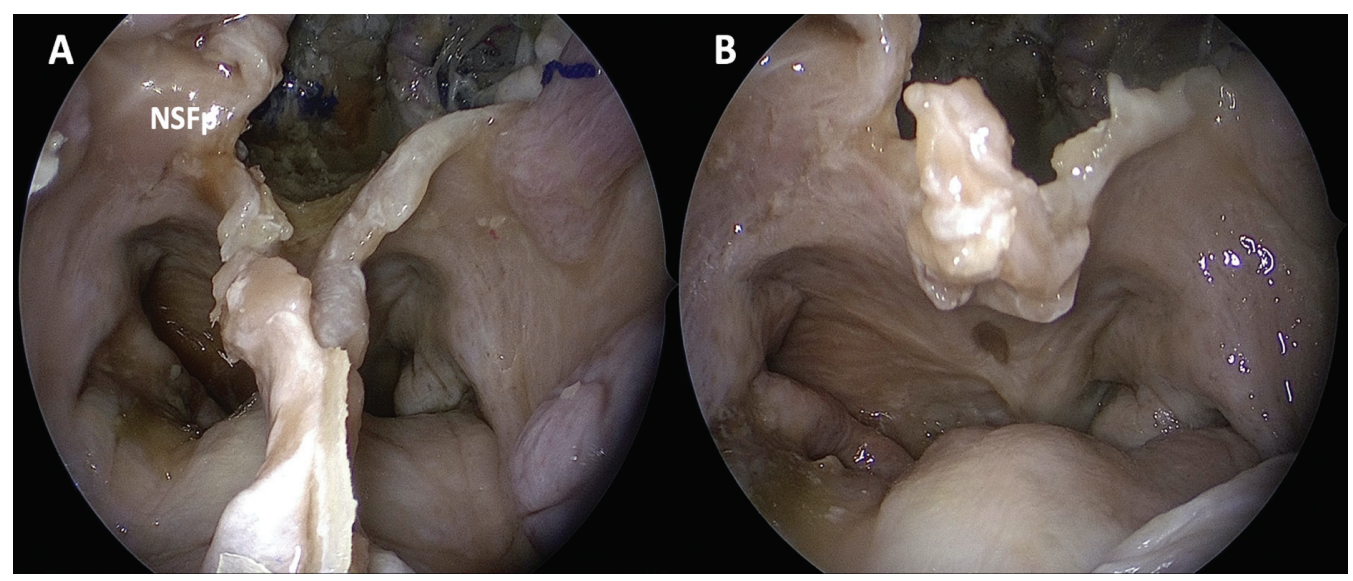

Fig. 1 Endonasal endoscopic view after harvesting a bilateral nasoseptal flap (NSF). (A) Before resection of the posterior nasal spine and vomer. (B) Ideal view of the field before making the upper-tongue flap (UTF). Abbreviation: NSFp: nasoseptal flap pedicle.

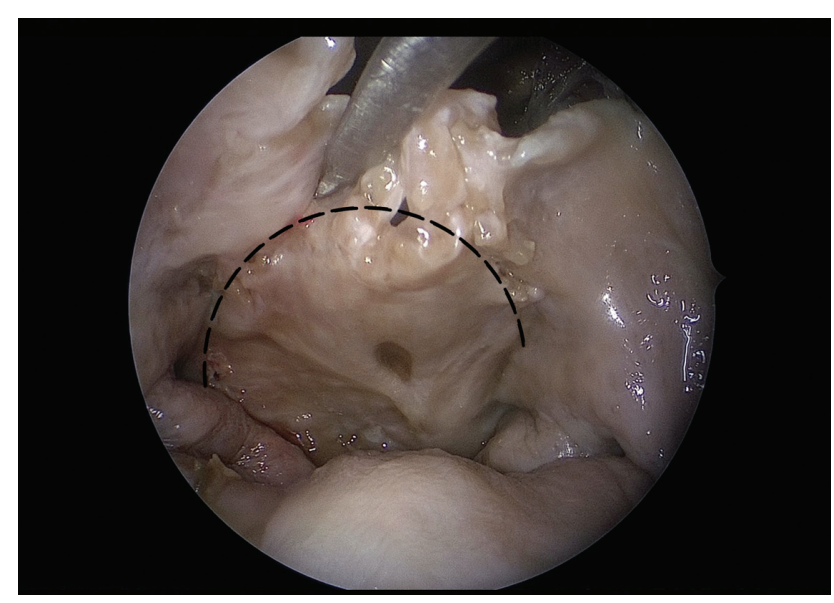

Fig. 2 Incision shaped like an inverted U.

\section{Method}

To demonstrate the technique, we used a human cadaver and accessed the nasal cavity and nasopharynx by endonasal endoscopy. Using a 0-degree endoscope, the UTF is made after harvesting a unilateral or a bilateral nasoseptal flap (NSF) and performing an outfracture of the inferior turbinates. Drilling of the posterior nasal spine and vomer provides better access to harvest the UTF, which will be inferiorly based in an incision shaped like an inverted $\mathrm{U}$ (-Fig. 1).

Two lateral and vertical incisions starting at the level of the middle third of the torus tubarius, and just posterior to it, are drawn on both sides. These incisions are connected by extending them superiorly toward the inferior edge of the NSF pedicle (-Fig. 2). Following this, one surgeon performs an en bloc dissection of the mucosa and muscles of the roof of the nasopharynx using the sharp edge of a freer, while another surgeon holds the superior edge of the UTF downwards using a Blakesley forceps. The dissection progresses caudally by freeing the longus capitis muscle until the imaginary line drawn between the middle third of both torus tubari ( - Fig. 3). Careful coagulation is performed with a monopolar suction device when necessary. Surgical dissection of the UTF using electrocautery should be

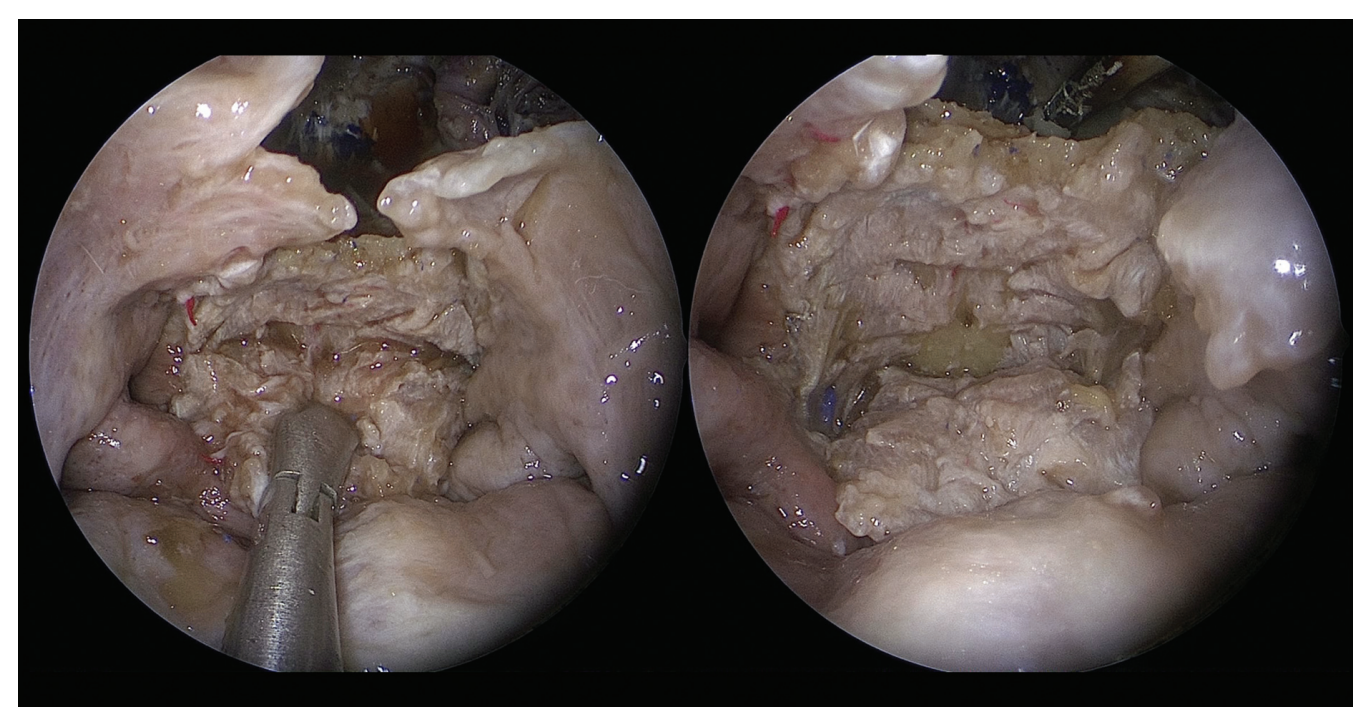

Fig. 3 Dissection of the soft tissue from the anterior edge of the sphenoid floor toward the nasopharynx. 


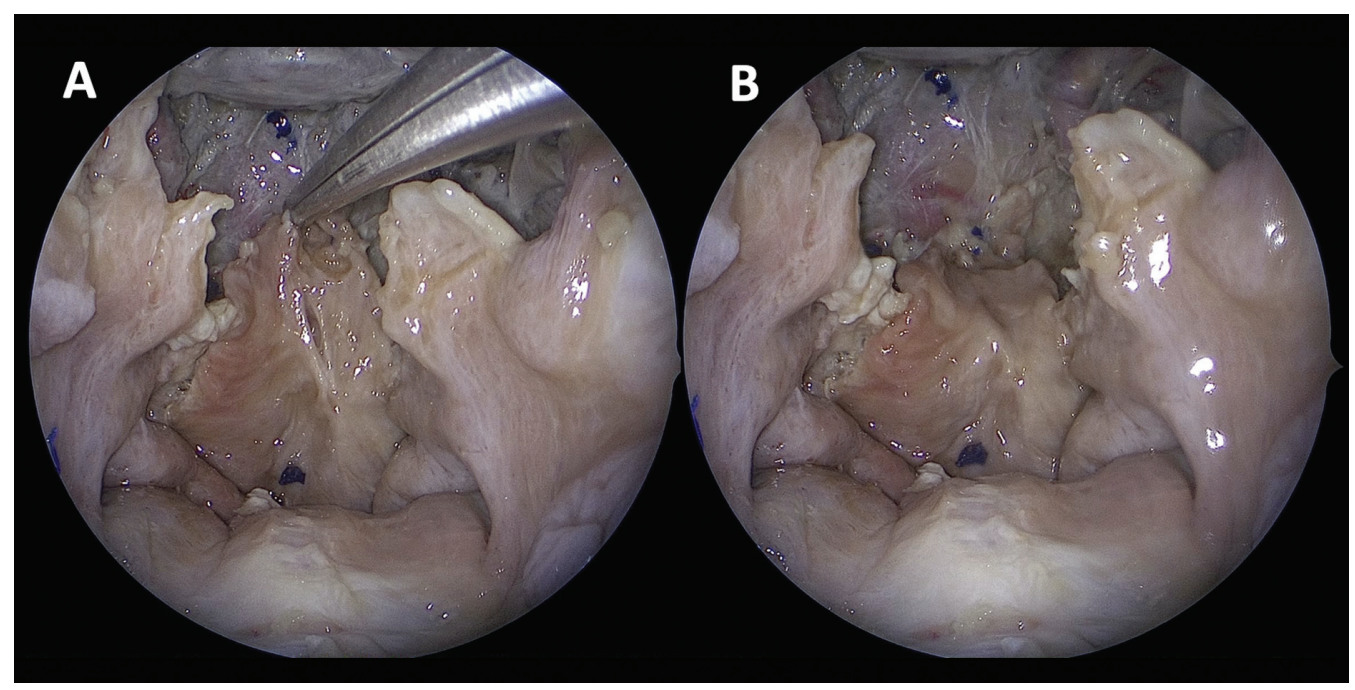

Fig. 4 (A) Length of the UTF. (B) Placement of the UTF covering the drilled area of the lower clivus.

avoided to preserve the length of the flap, which would otherwise suffer significant retraction.

The UTF is placed in the oropharynx, where the soft palate helps to hold it during the following procedure, by the end of which it is placed back in its original site ( -Fig. 4).

\section{Results}

We described a new nasopharyngeal flap with the shape of an upper tongue which is capable of cover the lower and middle portions of the clivus. It is also a modification of the previously described basipharyngeal flap, ${ }^{6}$ more extended anteriorly since the junction of the anterior wall of the sphenoid with its inferior wall.

\section{Discussion}

The UTF receives blood mainly from the ascending branch of the pharyngeal artery and descending branches of the lesser palatine arteries.

The UTF is particularly adequate as an alternative for the reconstruction of middle- and lower-clivus defects, and it is better used in association with an NSF in cases in which the NSF alone does not provide enough mucosal coverage. Further, by caudally displacing the soft tissues that are anterior to the inferior two-thirds of the clivus instead of transecting and resecting it, a midline aperture that sometimes remains open when using only an NSF is avoided.

\section{Conclusion}

The new nasopharyngeal flap can be used in the reconstruction of middle and lower clival resection.

\section{Conflict of Interests}

The authors have no conflict of interests to declare.

\section{References}

1 Hofmann E, Prescher A. The clivus: anatomy, normal variants and imaging pathology. Clin Neuroradiol 2012;22(02):123-139

2 Cavallo LM, Cappabianca P, Messina A, et al. The extended endoscopic endonasal approach to the clivus and cranio-vertebral junction: anatomical study. Childs Nerv Syst 2007;23(06): 665-671

3 Chakravarthi S, Gonen L, Monroy-Sosa A, Khalili S, Kassam A. Endoscopic Endonasal Reconstructive Methods to the Anterior Skull Base. Semin Plast Surg 2017;31(04):203-213

4 Hadad G, Bassagasteguy L, Carrau RL, et al. A novel reconstructive technique after endoscopic expanded endonasal approaches: vascular pedicle nasoseptal flap. Laryngoscope 2006;116(10): 1882-1886

5 Patel MR, Taylor RJ, Hackman TG, et al. Beyond the nasoseptal flap: outcomes and pearls with secondary flaps in endoscopic endonasal skull base reconstruction. Laryngoscope 2014;124(04): 846-852

6 Cárdenas Ruiz-Valdepeñas E, Kaen A, Pérez Prat G, Ambrosiani Fernandez J. How I do it: endoscopic endonasal approach to the inferior third of the clivus. Acta Neurochir (Wien) 2018;160(04): 741-745 